\title{
Sugarcane (Saccharum sp. Hybrid) Propagated in Headspace Renovating Systems Shows Autotrophic Characteristics and Develops Improved Anti-oxidative Response
}

\author{
Carlos Aragón • Luísa C. Carvalho • Justo González • \\ Maritza Escalona • Sara Amâncio
}

Received: 18 March 2008 / Accepted: 4 December 2008 /Published online: 16 December 2008

(C) Springer Science + Business Media, LLC 2008

\begin{abstract}
Previous results have shown that sugarcane plantlets micropropagated in Temporary Immersion Bioreactors (TIB) demonstrated a better morphology and physiological behaviour when compared to plantlets propagated in Gelled Medium (GM). The present work focuses on the onset of oxidative stress symptoms at transfer to ex vitro and during acclimatization. The specific ROS being produced were identified and tissue-located by infiltrating leaves with specific $\mathrm{O}_{2}{ }^{-}$and $\mathrm{H}_{2} \mathrm{O}_{2}$ staining dyes, respectively NBT and DAB. TIB plantlets showed trichomes stained with NBT and $\mathrm{DAB}$, their density decreasing with time. Stomata were coloured with NBT and DAB in GM and, at the end of acclimatization, plantlets from both systems presented the lowest level of staining of both stomata and trichomes. The response of the anti-oxidative system was also analysed through in vitro and in gel enzyme activities and transcription levels of genes for key response enzymes. At the end of the in vitro phase, GM plantlets showed higher activities of APX and MDHAR, while CAT, GR, GT and DHAR activities increased in TIB. At the end of acclimatization SOD and CAT increased mainly in TIB, while GM induced the increase of APX. The immunobloting of peroxiredoxins
\end{abstract}

Communicated by: Paulo Arruda \& Ray Ming

C. Aragón·J. González • M. Escalona

Laboratorio de Células y Cultivo Tejidos, Centro de Bioplantas,

Universidad de Ciego de Ávila,

Ciego de Ávila, Cuba

C. Aragón $\cdot$ L. C. Carvalho $\cdot$ S. Amâncio $(\triangle)$

Dpto. Botânica e Engenharia Biologica (DBEB/CBAA),

Instituto Superior de Agronomia,

Universidade Técnica de Lisboa,

Lisbon, Portugal

e-mail: samport@isa.utl.pt showed that Prxs were expressed at higher levels in TIB plantlets, some showing polymerization. The transcription of genes coding for key response enzymes was strongly upregulated in GM plantlets. In conclusion and comparing with GM, TIB produced plantlets closer to autotrophy and with improved mobilization of the anti-oxidative response.

Keywords Asc-glut cycle $\cdot$ Ex vitro growth . In vitro propagation $\cdot$ Oxidative stress $\cdot$ Peroxiredoxins

\section{Introduction}

The metabolic reprogramming event in plantlets after in vitro propagation is the main handicap for their ex vitro survival, thus conditioning the yield of the technique and representing one aspect in plant physiology which is seldom tackled with. The use of Temporary Immersion Bioreactors (TIB) has proven to be an alternative to gelled medium (GM) as an efficient propagation technique in what concerns plantlet morphology and physiology $[2,15,31]$. As a low cost option for the micropropagation of tropical crops (sugarcane, plantain, pineapple, etc.) this technique represents an important economical resource for the massive production of plantlets for the agricultural industry. Besides the traditional products derived from sugarcane (Sacharum sp.), which are sugar and cellulose, there are other products useful in animal feeding, alcoholic drink industry, etc. Recently, and due to new legislation on carbon dioxide emissions, sugarcane production became pivotal in the demand for bio-ethanol. Its requirement has already increased considerably and will be raised 3.28 fold by 2017 [3]. As a consequence, the micropropagation of this crop in TIB is one of the strategies proposed by several biotechnology 
companies to meet with the increasing demand. Therefore, it is necessary to develop and improve protocols for the transition of the plantlets from mixotrophic conditions to autotrophy during the acclimatization phase. The micropropagation of sugarcane, a $\mathrm{C}_{4}$ species, has been recently studied in TIB propagated plantlets, focusing on carbon metabolism [41], but not in what concerns the oxidative stress associated with micropropagation techniques. Usually, the headspaces accumulate several volatile compounds that can cause oxidative stress [42]. Leaf morphology, expansion and stomata functionality are also affected by the presence of ethylene and nitric oxide associated with abscisic acid production [24, 46]. Moreover, the transition of the plantlets to an ex vitro phase under high light intensity leads the way to the production of ROS (reactive oxygen species), which seems to be another pattern of response during the acclimatization phase [7; 47]. However, most of the studies have only applied GM and seldom compare it to TIB.

The use of TIB leads to an increase in the multiplication coefficient and to higher quality of the plants produced when compared with GM. TIB propagated plants show a physiology closer to autotrophy, which is favored by the possibility to recycle the air inside the vessels thus avoiding the growth of the plantlet in a closed environment [2, 15]. Several enzymes are known to display determinant roles in the anti-oxidative stress response, such as superoxide dismutase, catalase and those responsible for the functioning of systems such as the ascorbate-glutathione cycle [20].

Another relevant anti-oxidative response involves the differential expression of peroxiredoxins (Prxs) in different cellular compartments. These ubiquitous enzymes are unrelated to other peroxidase families but play a fundamental role in the anti-oxidant defense. They reduce hydrogen peroxide $\left(\mathrm{H}_{2} \mathrm{O}_{2}\right)$ and alkyl hydroperoxides and are active against a broader spectrum of peroxides than the $\mathrm{H}_{2} \mathrm{O}_{2}$-specific ascorbate peroxidase [37]. They undergo oxidation during the reaction of peroxide reduction and need to be reduced by electron donors such as glutaredoxins, thioredoxins, or cyclophilins before the next catalytic cycle, thus rendering them as low-efficiency enzymes. However, their abundance allows them to play a determinant role in the oxidative stress defense in specific cellular parts [22].

In this paper we show the patterns of response to photooxidative stress during acclimatization in sugarcane plantlets propagated under Gelled Medium (GM) or Temporary Immersion Bioreactors (TIB). We have monitored ROS accumulation through imaging, and measured the activities and expression levels of anti-oxidative enzymes. We present evidence that oxidative stress during acclimatization is directly related to the propagation method applied and that TIB propagated plants suffer less from stress and are able to overcome it better than GM plants.

\section{Methods}

\section{Plant Material, In Vitro and Ex Vitro Culture}

Sugarcane plantlets (Sacharum sp. hybrid) clone C91-301 were subjected to three sub-culture cycles of 21 days each in a culture medium containing Murashige and Skoog [36] salts and vitamins, supplemented with $30 \mathrm{~g} \mathrm{~L}^{-1}$ sucrose (w/v) and 1.33 $\mu \mathrm{M}$ 6-benzylaminopurine (BA). The elongation phase, a preparation of the shoots before acclimatization, lasted 21 days and two different techniques were applied, GM (Gelled Medium) and TIB (Temporary Immersion Bioreactors). In both techniques, the media used consisted of MS salts and vitamins supplemented with $30 \mathrm{~g} \mathrm{~L}^{-1}$ sucrose and without plant growth regulators. In GM, plantlets were placed in Magenta vessels (Sigma-Aldrich St. Louis, MO) of $250 \mathrm{~mL}$ total volume, containing $50 \mathrm{~mL}$ of media and Gelrite $2.0 \mathrm{~g} \mathrm{~L} \mathrm{~L}^{-1}$ with 5 shoots per vessel. TIB was performed in containers of $500 \mathrm{~mL}$ volume (Schott, Duran) containing 5 shoots per bioreactor and $200 \mathrm{~mL}$ of media [15]. Shoots were immersed for 4 min every $3 \mathrm{~h}$. PPFD was $45 \pm 5 \mathrm{mmol} \mathrm{m}^{-2} \mathrm{~s}^{-1}$ and the photoperiod was $16 / 8 \mathrm{~h}$ in both propagation techniques.

Microcuttings produced under TIB and GM were transplanted to pots containing a sterilised mixture of hydrated peat and perlite $(1: 1, \mathrm{v} / \mathrm{v})$ and placed in glass chambers (500E, Aralab, Porto Salvo, PT) of 450 L volume. Light was provided by fluorescent lamps Gro-Lux F18 W/GRO and, at plant level, photon flux density (PPFD) was $200 \pm$ $10 \mu \mathrm{mol} \mathrm{m} \mathrm{m}^{-2} \mathrm{~s}^{-1}$ and the photoperiod $16 / 8 \mathrm{~h}$. The programmed relative humidity $(\mathrm{RH})$ inside the glass chamber was obtained by an ultrasonic fog system controlled by a hygrometer. The initial value was set at $98 \%$ and was decreased until the $\mathrm{RH}$ in the glass chamber attained the ambient value at the end of acclimatization. Temperature was kept at $25 \pm 2^{\circ} \mathrm{C}$ during the light and $22 \pm$ $1^{\circ} \mathrm{C}$ in the dark.

The analyses were performed in leaves at time zero (day 0) of transfer to acclimatization, during the first seven days (day 1 to day 7) and on day 14 and 21 of ex vitro conditions in plantlets elongated under TIB and GM. Samples were collected in the middle of the light period.

\section{Histology and Image Analysis}

Stomatal index $(\%)$ was calculated as $(\mathrm{SF} /(\mathrm{SF}+\mathrm{EF})) \times 100$ where SF and EF are respectively de number of stomata and epidermal cells per unit leaf area of the first leaf fully expanded [5]. To calculate trichome index, the number of trichomes (TF) replaces SF in the above formula.

The detection of ROS was carried out as described by Fryer et al. [19]. Leaves from sugarcane plantlets were 
detached on day 0 and on day 14 of ex vitro growth in a $2 \mathrm{mM}$ EDTA solution $\mathrm{pH}$ 5.5, incubated in $5 \mathrm{mM} \mathrm{3,3}$, diaminobenzidine (DAB) $\mathrm{pH} 3.8$ to detect $\mathrm{H}_{2} \mathrm{O}_{2}$ or in $6 \mathrm{mM}$ nitroblue tetrazolium (NBT) to detect $\mathrm{O}_{2}{ }^{-}$, and cleared in ethanol at $60^{\circ} \mathrm{C}$.

\section{Extraction for Enzyme Activity Assays}

The extracts for measuring enzyme activities were prepared at $4{ }^{\circ} \mathrm{C}$ from $0.5 \mathrm{~g}$ of frozen leaf material. The material was ground using mortar and pestle, and $50 \%$ (w/w) polyvinylpolypyrrolidone was added. The extraction buffer was Tris- $\mathrm{HCl} 0.35 \mathrm{M}$ (pH 8) supplemented with EDTA $20 \mathrm{mM}$; DETC $11 \mathrm{mM}$, cystein $15 \mathrm{mM}$, and $0.2 \mathrm{mM}$ PMSF. Extracts were centrifuged at $27,000 \mathrm{~g}$ for $10 \mathrm{~min}$ at $4^{\circ} \mathrm{C}$ and the supernatants, desalted through PD-10 columns (Amersham Pharmacia Biotech, Buckinghamshire, UK), were used for all the determinations. Protein was determined by the method of Bradford [4] using a commercial kit (Bio-Rad, Hercules, CA).

\section{Preparation of Mesophyll and Boundle Sheath Extracts}

For the extraction of mesophyll tissue, leaf segments were placed between a roller and an aluminum block (both kept at $4^{\circ} \mathrm{C}$ ), according to Leegood [29]. The roller was moved along the length of the leaf so that slight pressure was applied. This resulted in the displacement of mesophyll sap from the leaf blade into the extraction buffer was placed beneath the leaf. The pressure was insufficient to disturb the bundle-sheath strands that remained intact. The remaining of the process of protein extraction for both compartments and the buffer used are described above.

In all cases, the purity of the fractions was determined by measuring the bundle sheath and mesophyll marker enzymes Rubisco and phosphoenolpyruvate carboxylase (PEPC), respectively. Maximal Rubisco activity was determined according to Carvalho et al. [6]. PEPC activity was measured according to the method of Van Quy et al. [48]

\section{Enzyme Activity Assays}

The activities of all enzymes were assayed using the extracts described above as samples. Ascorbate peroxidase (APX) (EC 1.11.1.11) activity was determined at $25^{\circ} \mathrm{C}$ using a modification of the method of Hossain and Asada [23]. The reaction mixture of $1 \mathrm{~mL}$ contained $50 \mathrm{mM}$ potassium phosphate-KOH $\mathrm{pH} 7.5,0.5 \mathrm{mM}$ AsA, $0.1 \mathrm{mM}$ EDTA and the enzyme sample (ca $14 \mu \mathrm{g}$ protein). The oxidation rate of AsA was estimated between 1.0 and $60 \mathrm{~s}$ after starting the reaction by adding $0.2 \mathrm{mM} \mathrm{H}_{2} \mathrm{O}_{2}$.
Dehydroascorbate reductase (DHAR) (EC 1.8.5.1) activity was determined according to the method of Dalton et al. [10] following the increase in $\mathrm{A}_{265}$ due to ascorbate formation $\left(\varepsilon_{265}=14 \mathrm{mM}^{-1} \mathrm{~cm}^{-1}\right)$. The assay mixture contained $0.1 \mathrm{M}$ Hepes-KOH buffer pH 7.0, 2.5 mM GSH, 0.5 mM DAsA, $0.1 \mathrm{mM}$ EDTA and the enzyme sample ( $c$ a $35 \mu \mathrm{g}$ protein), in a final volume of $1 \mathrm{~mL}$. The reaction rate was corrected for the nonenzymatic reduction of DAsA by GSH. A factor of 0.98 to account for the small contribution to the absorbance by GSSG was also considered.

Monodehydroascorbate reductase (MDHAR) (EC 1.6.5.4) activity was determinated by following the decreased in $\mathrm{A}_{340}$ due to NADH oxidation, as described [23] in a coupled test system, in which the monodehydroascorbate radical is produced by ascorbate oxidase in Tris- $\mathrm{HCl}$ buffer, $\mathrm{pH} 7.5$, containing $0.2 \mathrm{mM} \mathrm{NADH}, 2.5 \mathrm{mM}$ AsA, 0.5 units ascorbate oxidase (from Cucurbita species, Sigma-Aldrich St. Louis, MO) and enzyme extract (ca $14 \mu \mathrm{g}$ protein) in a final volume of $1 \mathrm{~mL}$ at $25^{\circ} \mathrm{C}$.

Glutathione reductase (GR) (EC 1.6.4.2) was assayed by the decrease in $A_{340}$ due to NADPH oxidation $\left(\epsilon_{340}=\right.$ $6.22 \mathrm{mM}^{-1} \mathrm{~cm}^{-1}$ ), as described [44], in a reaction mixture

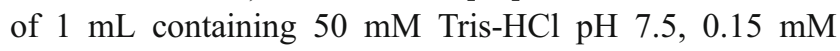
NADPH, $0.5 \mathrm{mM}$ GSSG, $3 \mathrm{mM} \mathrm{MgCl} 2$ and the sample ( $c a$ $35 \mu \mathrm{g}$ protein).

Superoxide dismutase (SOD) (EC 1.15.1.1) was assayed by the ferricytochrome $\mathrm{C}$ method using xanthine/xanthine oxidase as the source of superoxide radicals [34] in a $1 \mathrm{~mL}$ reaction mixture containing $50 \mathrm{mM}$ potassium phosphate$\mathrm{KOH}$ buffer $\mathrm{pH}$ 7.6, 0.1 mM EDTA, $0.01 \mathrm{mM}$ cytochrome $\mathrm{C}, 0.05 \mathrm{mM}$ xanthine, 0.03 units xanthine oxidase and the enzyme sample ( $c a 14 \mu \mathrm{g}$ protein).

Catalase (CAT) (EC 1.11.1.6) is directly determined by the decomposition of $\mathrm{H}_{2} \mathrm{O}_{2}$ at $240 \mathrm{~nm}$ in a $1 \mathrm{~mL}$ mixture containing $50 \mathrm{mM}$ potassium phosphate- $\mathrm{KOH} \mathrm{pH}$ 7.0, $10 \mathrm{mM} \mathrm{H}_{2} \mathrm{O}_{2}$ and the sample (ca $35 \mu \mathrm{g}$ protein).

Glutathione transferase (GT) (EC 2.5.1.18) was assayed as the increased of $\mathrm{A}_{340}$ due to the conjugation of GSH to 1chloro-2,4dinitrobenzene (CDNB), as described [14], in $100 \mathrm{mM}$ potassium phosphate-KOH, pH 7.0, containig $2 \mathrm{mM}$ CDNB, $2 \mathrm{mM}$ GSH and enzyme source (ca 14$35 \mu \mathrm{g}$ protein).

\section{Native PAGE and Gel Activity Staining}

Native Polyacrylamide Gel and Gel Activity Staining Isoforms of CAT, SOD, APX, and GR were separated in nondenaturing polyacrylamide gels by the procedure of Laemmli [28]. Equal amounts of protein extracts $(25 \mathrm{mg})$ were loaded on 7\% (CAT) or 10\% (SOD, GR, and APX) polyacrylamide gels.

For SOD, the gel was stained according to Rao et al. [40]. Gels were incubated for $30 \mathrm{~min}$ in $50 \mathrm{mM}$ potassium 
phosphate buffer ( $\mathrm{pH}$ 7.8) containing $1 \mathrm{mM}$ EDTA. To identify $\mathrm{KCN}$ and $\mathrm{H}_{2} \mathrm{O}_{2}$ sensitive isoforms, this incubation solution contained $3 \mathrm{mM} \mathrm{KCN}$ or $5 \mathrm{mM} \mathrm{H}_{2} \mathrm{O}_{2}$, respectively. This step was followed by incubation in $50 \mathrm{mM}$ potassium phosphate buffer ( $\mathrm{pH} 7.8$ ) containing $0.245 \mathrm{mM}$ nitroblue tetrazolium, $33.2 \mathrm{mM}$ riboflavin, and $0.2 \%$ tetramethyl ethylene diamine (TEMED) in darkness for $30 \mathrm{~min}$. before illumination to visualize SOD isoforms or bands [12].

To visualize the CAT profile, gels were stained by the procedure of Anderson et al. [1]. The gels were incubated in $3.27 \mathrm{mM} \mathrm{H}_{2} \mathrm{O}_{2}$ for $25 \mathrm{~min}$, rinsed in distilled water, and then stained in a solution containing $1 \%(\mathrm{w} / \mathrm{v})$ potassium ferricyanide and $1 \%(\mathrm{w} / \mathrm{v})$ ferric chloride.

Isoforms of APX were visualized by incubating the gels for $30 \mathrm{~min}$. in $50 \mathrm{mM}$ potassium phosphate buffer ( $\mathrm{pH} 7.0$ ) containing $2 \mathrm{mM}$ ascorbate, followed by an incubation in the same buffer containing $4 \mathrm{mM}$ ascorbate and $2 \mathrm{mM} \mathrm{H}_{2} \mathrm{O}_{2}$ for $20 \mathrm{~min}$. Finally, gels were stained in $50 \mathrm{mM}$ potassium phosphate buffer ( $\mathrm{pH} 7.8)$ containing $28 \mathrm{mM}$ TEMED and $2.45 \mathrm{mM}$ nitroblue tetrazolium for $15 \mathrm{~min}$.

GR was detected by incubating the gels for $60 \mathrm{~min}$ in darkness in $50 \mathrm{mM}$ Tris- $\mathrm{HCl}$ buffer $(\mathrm{pH} 7.5)$ containing $0.5 \mathrm{mM}$ 3-(4,5-dimethylthiazol-2-4)-2,5-diphenyl tetrazolium bromide, $0.7 \mathrm{mM}$ 2,6-dichlorophenolindophenol, $3.4 \mathrm{mM}$ GSSG, and $0.5 \mathrm{mM}$ NADPH. The staining reaction was stopped by adding $7.5 \%(\mathrm{v} / \mathrm{v})$ glacial acetic acid to the staining buffer.

Relative quantification of isoenzyme activities was determined using the software Quantity One (Bio-Rad, Hercules, CA).

\section{Peroxiredoxin Activity and Immunoblotting}

Reduction of $\mathrm{H}_{2} \mathrm{O}_{2}$ by peroxiredoxins was quantified through a non-enzymatic, DTT-dependent activity assay by measuring the decrease in $\mathrm{H}_{2} \mathrm{O}_{2}$ concentration in the assay solution. The assay contained $100 \mathrm{mM} \mathrm{K}-\mathrm{Pi}$ buffer ( $\mathrm{pH}$ 7.0), 0.3$3 \mu \mathrm{M}$ Prx, $10 \mathrm{mM}$ DTT, and $100 \mu \mathrm{M} \mathrm{H}_{2} \mathrm{O}_{2}$ in a total volume of $1 \mathrm{~mL}$. The reaction was initiated with $\mathrm{H}_{2} \mathrm{O}_{2}$ and stopped with $800 \mu \mathrm{L}$ of trichloroacetic acid $(12.5 \%[\mathrm{w} / \mathrm{v}])$ to an aliquot of $50 \mu \mathrm{L}$ of assay solution. After adding $200 \mu \mathrm{L}$ of $10 \mathrm{mM} \mathrm{Fe}\left(\mathrm{NH}_{4}\right)_{2}\left(\mathrm{SO}_{4}\right)_{2}$ and $100 \mu \mathrm{L}$ of $2.5 \mathrm{M} \mathrm{KSCN}$, the $A_{480}$ was measured to quantify the $\mathrm{H}_{2} \mathrm{O}_{2}$ contents of the solution, and $\mathrm{H}_{2} \mathrm{O}_{2}$ reduction rates were calculated.

Polyclonal antibodies against cytosolic type II Prx C, chloroplast-located type II Prx E, chloroplast-located 2-cys Prx, chloroplast-located Prx Q and mitochondria-located type II Prx F, kindly supplied by Professor K-J Dietz (Bielefeld University, Germany). Western blot analysis was performed by electrophoretic transfer of proteins, separated by SDS-PAGE, to a nitrocellulose membrane (Millipore) and probed with the respective antibodies using the procedure described by Ferreira et al. [16].
RNA Isolation and cDNA Preparation for Real-Time PCR

Total RNA from leaves was extracted by adapting the method described by Chang et al. [9]. CTAB (2\%) was complemented with PVPP $(2 \%$, w/w), Trizma-HCl $100 \mathrm{mM}$, $25 \mathrm{mM} \mathrm{Na}_{2}$ EDTA, and $2 \mathrm{M} \mathrm{NaCl} ; \mathrm{pH} 8.0$ and the buffer was heated to $85^{\circ} \mathrm{C}$ prior to the addition of $400 \mu \mathrm{L} \mathrm{2-}$ mercarptoethanol. Tissues were reduced to powder in liquid $\mathrm{N}_{2}$ and $20 \mathrm{~mL}$ extraction buffer were added. The same volume of chlorophorm:isoamyl alcohol 24:1 was then added. This step was followed by a centrifugation at $12,000 \mathrm{~g}$ for $30 \mathrm{~min}$ at $20^{\circ} \mathrm{C}$ and repeated once. The aqueous phase was transferred to a new tube, and a $1 / 4 \mathrm{LiCl}$ $10 \mathrm{M}(\mathrm{V} / \mathrm{V})$ was added. The sample was incubated at $0^{\circ} \mathrm{C}$ overnight and after centrifugation at $12,000 \mathrm{~g}$ for $20 \mathrm{~min}$. at $4^{\circ} \mathrm{C}$. The pellet was recovered and $1.5 \mathrm{~mL}$ of SSTE buffer (Trizma-HCl $10 \mathrm{mM}, 1 \mathrm{mM} \mathrm{Na} 2$ EDTA, $1 \mathrm{M} \mathrm{NaCl} ; 0.5 \%$ SDS (w/v), pH 8.0.) previously heated to $37^{\circ} \mathrm{C}$ was added. The same volume of chlorophorm:isoamyl alcohol (24:1) was added and this step was followed by a centrifugation at $12,000 \mathrm{~g}$ for $10 \mathrm{~min}$ at $20^{\circ} \mathrm{C}$ and repeated once. Ethanol $100 \%$ (2.5 volumes) was added and the samples were incubated for $1 \mathrm{~h}$ at $80^{\circ} \mathrm{C}$ and then washed with ethanol $70 \%$. After drying, the RNA was resuspended in the desired volume of distilled water. RNA samples were treated with RQ1 RNase-Free DNase (Promega, Madison, WI) and reverse transcribed using random hexamers and Superscript II RNase H-reverse transcriptase (Invitrogen, Carlsbad, CA) according to the manufacturer's recommendations.

\section{Real-Time PCR and Quantification of mRNA Levels}

Primer pairs used for amplification of all the genes studied are presented in Table 1. The genomic sequences for sugarcane available in the GeneBank database were used. The real-time PCR was performed in $20 \mu \mathrm{L}$ of reaction mixture composed of cDNA, $0.5 \mu \mathrm{M}$ gene-specific primers and master mix iQ SYBR Green Supermix (BioRad, Hercules, CA) using an iQ5 Real Time PCR (BioRad, Hercules, CA). Amplification of PCR products was monitored via intercalation of SYBR-Green (included in the master mix). The following program was applied: initial polymerase activation, $95^{\circ} \mathrm{C}, 3 \mathrm{~min}$.; then 40 cycles at $95^{\circ} \mathrm{C} 15 \mathrm{~s}$ (denaturation), $57^{\circ} \mathrm{C} 30 \mathrm{~s}$ (annealing), $72^{\circ} \mathrm{C}$ $20 \mathrm{~s}$ (extension) with a single fluorescence reading taken at the end of each cycle. Each run was completed with a melting curve analysis to confirm the specificity of amplification and confirm the lack of primer dimmers. Further, RT-PCR products were resolved on $2 \%(\mathrm{w} / \mathrm{v})$ agarose gels run at $4 \mathrm{~V} \mathrm{~cm}^{-1}$ in Tris-acetate-EDTA buffer (TAE), along with a 50-bp DNA-standard ladder (Invitrogen $\mathrm{Gmb} \mathrm{H}$ ), to confirm the existence of a single product of the desired length. 
Table 1 Real-time PCR primers used for evaluation of mRNA levels of the enzymes studied

\begin{tabular}{|c|c|c|c|}
\hline \multirow[t]{2}{*}{ Protein name, intracellular localization } & \multirow[t]{2}{*}{ RNA gene bank number } & \multicolumn{2}{|l|}{ Primers } \\
\hline & & Name & Sequence \\
\hline \multirow[t]{2}{*}{ Actin } & \multirow[t]{2}{*}{ AY742219.1 } & ACT-F & 5'-GGACCTCTACGGCAACATTGTG-3' \\
\hline & & ACT-R & 3'-CCAGACTCATCATACTCCTCCTTCG-5' \\
\hline \multirow[t]{2}{*}{ MnSOD (mitochondria) } & \multirow[t]{2}{*}{ CA242138 } & MSOD-F & 5'-AGAAGCACCACGCCACCTAC-3' \\
\hline & & MSOD-R & 3'-CACCCATCCAGATCCTTGTAAAGC-5' \\
\hline \multirow[t]{2}{*}{ CuZnSOD (chloroplast, cytosol) } & \multirow[t]{2}{*}{ TC48812 } & CZSOD-F & 5'-GGCTGTTGCTGTGCTTGGTAG-3' \\
\hline & & CZSOD-F & 3'-TGGCGGTTCTCATCTTCTGGTG-5' \\
\hline \multirow[t]{2}{*}{ CAT } & \multirow[t]{2}{*}{ EF566889.1 } & CAT-F & 5'-GGCAAGAGCGGTTCATCAAGAG-3' \\
\hline & & CAT-R & 3'-TGAGCGAAGCAGAGTTCAGTCC-5' \\
\hline \multirow[t]{2}{*}{ APX } & \multirow[t]{2}{*}{ CF570493 } & APX-F & 5'-TACGGACGAGTTGATGTTACAGGAC-3' \\
\hline & & APX-R & 3'-ACCTTCCAAGTGTATGTGCTCCAG-5' \\
\hline \multirow[t]{2}{*}{ GR (cytosol) } & \multirow[t]{2}{*}{ TC57827 } & GR-F & 5'-TAGTGTATGGGCTGTGGGTGATG-3' \\
\hline & & GR-R & 3'-GCTTGGATATGCTGTTCTTCATTGG-5' \\
\hline \multirow[t]{2}{*}{ Prx1 (mytochondria) } & \multirow[t]{2}{*}{ AY796053.1 } & Prx1-F & 5'-GCCTATCTGCCGTGTCGTCTG-3' \\
\hline & & Prx1-R & 3'-GCCTGTGTCTCAACTCGCATTTC-5' \\
\hline
\end{tabular}

To generate a baseline-subtracted plot of the logarithmic increase in fluorescence signal $(\Delta \mathrm{Rn})$ versus cycle number, baseline data were collected between the cycles 5 and 17 . All amplification plots were analysed with an $R_{n}$ threshold of 0.2 to obtain $\mathrm{C}_{\mathrm{T}}$ (threshold cycle) and the data obtained were exported into a MS Excel workbook (Microsoft Inc.). In order to compare data from different PCR runs or cDNA samples, $C_{T}$ values were normalized to the $C_{T}$ value of Act2, a housekeeping gene expressed at a relatively high and constant level. Gene expression was normalized to that of $A c t 2$ by subtracting the $\mathrm{C}_{\mathrm{T}}$ value of $A c t 2$ from the $\mathrm{C}_{\mathrm{T}}$ value of the gene of interest.

\section{Statistical Analysis of the Results}

All experiments were performed three times with three repetitions each. All statistical analyses were carried out using SPSS version 12 [39]. All situations were analysed using non-parametric analyses, either Kruskall-Wallis H. and C-Dunnett or Mann Whitney, both at $5 \%$ significance level.

\section{Results}

The present work compares the distinct patterns of response of sugarcane plantlets when subjected to propagation under Temporary Immersion Bioreactors (TIB) and Gelled Medium $(\mathrm{GM})$. Analyses were performed at time zero (day 0) of transfer, and plantlets were monitored at intervals during the 21 days of acclimatization.

Histological Analyses and Imaging of ROS

The histological analyses of leaf structures (stomata and trichomes) are shown in Figs. 1 and 2. Leaves were collected, infiltrated with NBT (left) or DAB (right), as described in Materials and Methods. The purple formazan deposits, which result from the reaction of NBT with $\mathrm{O}_{2}{ }^{-}$identify the regions where this molecule is produced or accumulated. $\mathrm{H}_{2} \mathrm{O}_{2}$ was imaged in leaves infiltrated with $\mathrm{DAB}$ which produces a brown polymerization product from its reaction with $\mathrm{H}_{2} \mathrm{O}_{2}$, in the presence of peroxidases. The staining patterns were similar in plantlets propagated in GM and TIB, the only difference being the index of stained structures per leaf (Fig. 2). Cells surrounding the stomata guard cells were stained for both ROS (Fig. 1). Trichomes showed a unique pattern of staining (Fig. 1b), with formazan deposits (NBT staining) accumulating in the glandular structure in the second cell of bicellular trichomes. When these structures were stained with $\mathrm{DAB}$ the brown polymerization products accumulated preferentially in the cell wall.

Fig. 2 shows total and stained stomatal indexes (Fig. 2a) and total and stained trichome indexes (Fig. 2b) of GM and TIB plantlets, on day 0 and day 14 of ex vitro growth. On day 0 both stomatal and trichome indexes were significantly higher in GM cultured plantlets as compared to TIB, and so was the percentage of colored stomata and trichomes. After 14 days ex vitro both indexes decreased significantly in GM plantlets while TIB plantlets maintained trichome and stomata indexes similar to day 0 .

Anti-oxidative Response at the Level of Enzyme Activity

The total activities of several photo-oxidative stress response enzymes measured at the end of GM and TIB in vitro phase (day 0 ) and daily during the first seven days and on day 14 and 21 of acclimatization are represented in Fig. 3. On day $0 \mathrm{GM}$ plantlets showed significantly higher activities of MDHAR and APX, TIB conditions were 
Fig. 1 Imaging of ROS accumulation in stomata (a) and trichomes (b) of sugarcane plantlets stained with NBT for superoxide radical visualization (left) and with DAB for hydrogen peroxide visualization (right). Scale bars are represented in each image a)

NBT staining

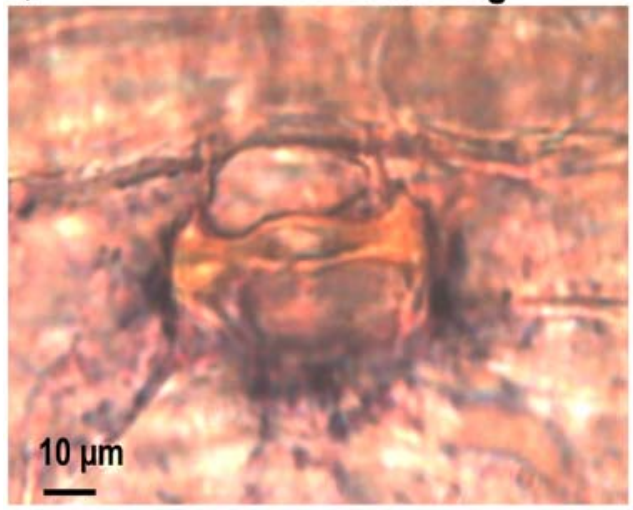

b)

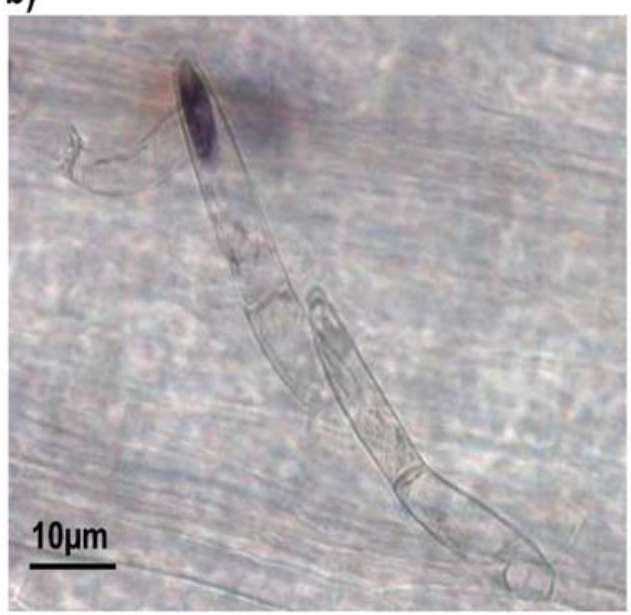

DAB staining
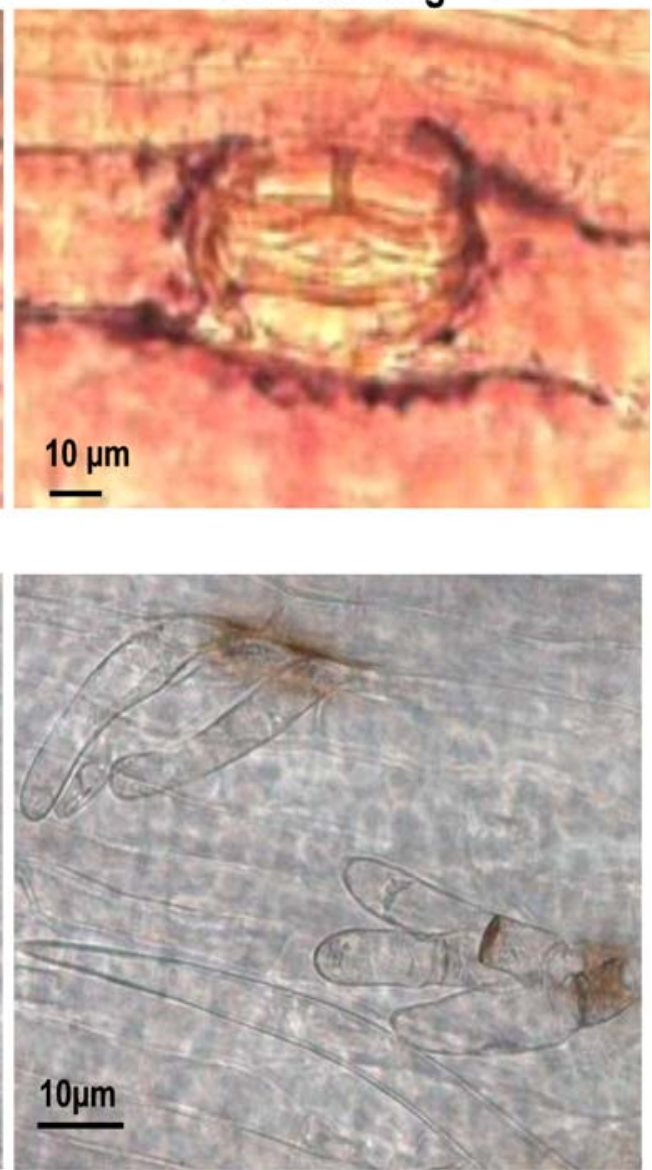

responsible for higher activities of CAT, GR, DHAR and GT while SOD values were similarly low in both propagation methods. The activities monitored during the acclimatization period in plantlets grown under both propagation methods showed that SOD activity increased significantly in TIB grown plantlets and was almost residual in GM plantlets. During the first seven days, enzyme activity showed a large range of values, mostly, in TIB, with peaks on days 3 and 7 for SOD, day 3 for CAT, days 3 and 5 for GR and day 4 for MDHAR. TIB plantlets maintained higher SOD, CAT, DHAR and MDHAR activities along the remaining acclimatization period, while GR, APX, Prx and GT activities were equivalent in GM and TIB plantlets.on day 21. Total Prx activity decreased slowly from day 0 on in both treatments.

By applying the inhibitors described in Materials and Methods, in gel enzyme activity enabled the identification of one Mn-SOD and three CuZn-SOD, whose relative activity was quantified (Table 2). Mn-SOD (SOD-D) increased slightly from day 0 to day 7 and remained high until day 21 in both GM and TIB. Two of the three $\mathrm{CuZn-}$ SOD isoenzymes were constitutive (SOD-A and B) and showed constant activity levels in both propagation methods and through time while SOD-C was present on

Fig. 2 Coloured stomata (a) and trichome (b) index in GM and TIB propagated plantlets prior to transfer to ex vitro (day 0 ) and after acclimatization (day 14). Values indicated by different letters are significantly different at $5 \%$ level by C-Dunnett Multiple Range Test $(n=9)$
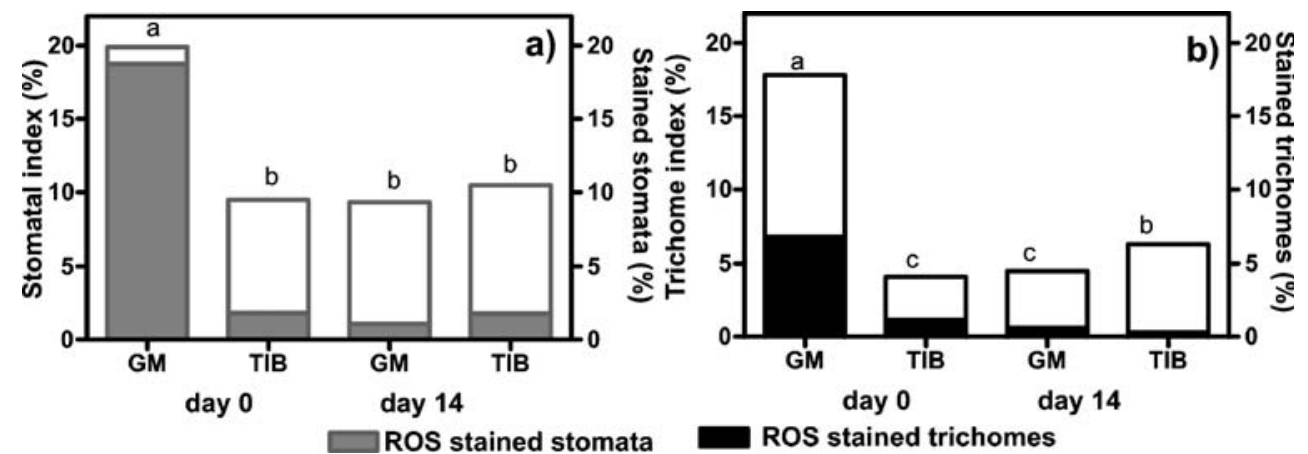
Fig. 3 Total soluble enzyme activities in leaves of sugarcane plantlets propagated under GM and TIB at the moment of transfer (day 0) and during acclimatization. Activities are expressed as follows: CAT, SOD, units per milligram of protein; APX, micromoles of AsA oxidized per minute per milligram of protein; DHAR, micromoles of AsA formed per minute per milligram of protein; GR, micromoles of NADPH oxidized per minute per milligram of protein; Prx, micromoles of $\mathrm{H}_{2} \mathrm{O}_{2}$ reduced per minute per milligram of protein. For clarity purposes, different scales were used. Values indicated by different letters are significantly different at $5 \%$ level by C-Dunnett Multiple Range Test
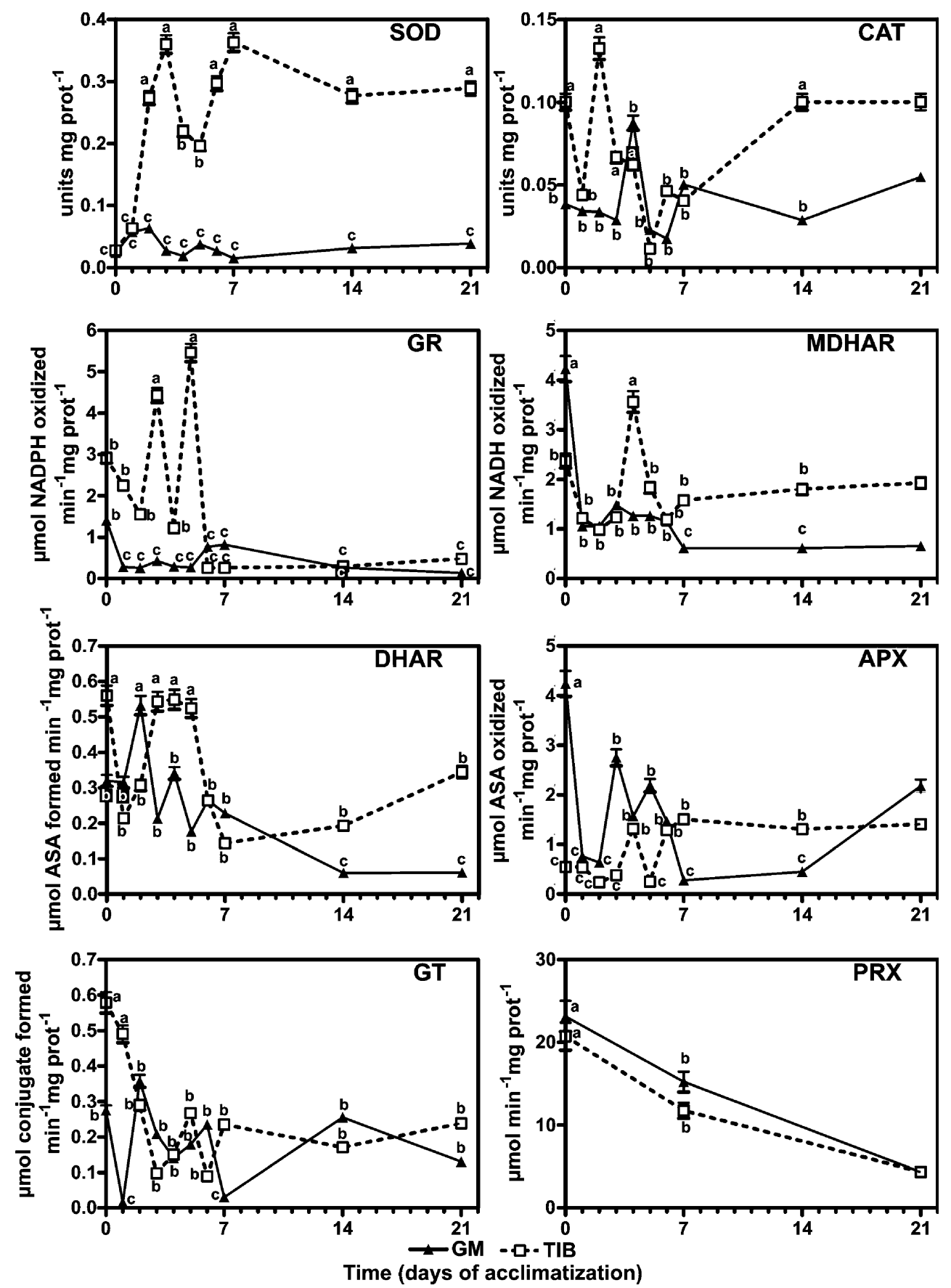

day 0 in both treatments and also on day 21 in TIB. In TIB, while the difference in total activity between day 0 and day 21 is six fold, in gel SOD activities increase between 10 and $17 \%$. Apparently, high activities in the extracts were not reproduced proportionally in gel. CAT showed a single band with similar levels of activity only on day 0 in GM and TIB. Once again, the activities in the extracts were not reproduced in gel. APX in gel activity revealed two isoenzymes, neither showing significantly different activities than in vitro. Also, the two fold difference in activity between days 0 and 21 in TIB was not visible in gel. Four
GR isoenzymes were detected, respectively of 55, 54, 46 and $45 \mathrm{kDa}$ (GR-A through D; Table 2 and Fig. 4). To elucidate whether GR isoenzymes are related to a possible distinction of isoforms between bundle sheath and mesophyll cells, we designed an experiment enabling the physical separation of proteins between those two types of cells (see Material and Methods). To confirm the tissue separation we measured RuBisCO and PEPC enzyme activities in both cell types. In a successful separation, there should be a significantly higher activity of RuBisCO in the bundle sheath and of PEPC in the mesophyl (Pastori 
Table 2 SOD, CAT, APX and GR isoenzyme in gel activities in leaves of acclimatizing sugarcane plantlets propagated under GM and TIB were quantified in relation to the value at day 0 (day $0=100 \%$ activity)

\begin{tabular}{|c|c|c|c|c|c|c|}
\hline & \multicolumn{3}{|l|}{ GM: } & \multicolumn{3}{|c|}{ TIB: } \\
\hline & 0 & 7 & 21 & 0 & 7 & 21 \\
\hline APX-A & 100 & 99 & 95 & 96 & 98 & 96 \\
\hline APX-B & 100 & 97 & 93 & 97 & 94 & 94 \\
\hline GR-A & 100 & 83 & 89 & 95 & 88 & 92 \\
\hline GR-B & 100 & 80 & 122 & 86 & 85 & 89 \\
\hline GR-C & 100 & 104 & 121 & 106 & 109 & 111 \\
\hline GR-D & 100 & 92 & 106 & 92 & 94 & 101 \\
\hline CAT & 100 & - & - & 101 & - & . \\
\hline SOD-A & 100 & 109 & 105 & 99 & 101 & 97 \\
\hline SOD-B & 100 & 104 & 103 & 98 & 101 & 101 \\
\hline SOD-C & 100 & - & - & 113 & - & 100 \\
\hline SOD-D & 100 & 110 & 111 & 104 & 117 & 107 \\
\hline
\end{tabular}

Total protein extracts were subjected to native PAGE followed by activity staining for the four enzymes. Discrimination between SOD isoforms was revealed by inhibition with $\mathrm{H}_{2} \mathrm{O}_{2}$ and $\mathrm{KCN}$. Quantification was performed using the software Quantity One (Bio-Rad, Hercules, CA)

et al. 2000). RuBisCO activity in the bundle sheath cells was 3.5 fold higher than in the mesophyl (Table 3), while the opposite was observed for PEPC activity, 2.23 fold higher in mesophyl cells. Using these extracts, in vitro GR enzyme activity was 1.5 fold higher in bundle sheath cells (Table 3). Further, in gel GR activity performed with extracts of the two separate tissues showed that GR-A and GR-C are present in the bundle sheath and GR-B and GR-D in the mesophyl (data not shown). Only the bundle sheath isoform GR-C shows a tendency for higher activity at the end of ex vitro growth. In GM plantlets, in gel isozymes and total activitiy of GR (Fig. 3) follow an equivalent trend; in TIB, the decrease in total activity from day 0 to day 21 (Fig. 3) is not apparent in Fig. 4.

\section{Detection of Different Peroxiredoxins Using Specific} Antibodies

The immunodetection of five different Prx (Fig. 5) revealed the response of Prx isoenzymes present in

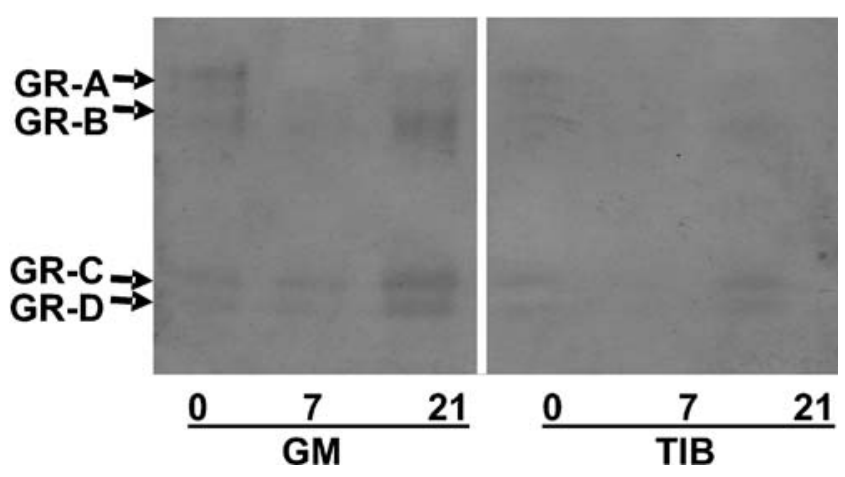

Fig. 4 GR isoenzyme in gel activity in leaves of acclimatizing sugarcane plantlets propagated under GM and TIB. Total protein extracts were subjected to native PAGE followed by activity staining specific organelles (chloroplast, mitochondria and cytosol). Chloroplast Prxs showed different patterns of response: 2-Cys Prx was present in the highest concentration as a single band of circa $20 \mathrm{kDa}$, while Type II E and Prx Q were present in lower amounts and revealed polymerization bands, particularly in TIB (circa $60 \mathrm{kDa}$ in Prx Q and $40 \mathrm{kDa}$ in type II E). Type II Prx C (cytosol) was detected in low amount while the mitochondrialocated type II Prx F was present in high levels, with higher intensity in TIB as compared to GM and evidencing a $40 \mathrm{kDa}$ polymerization band.

Expression of Genes Taking Part in the Anti-oxidative Defense System

The expression of sugarcane $A P X, C A T, M n S O D, C u Z n$ $S O D, G R$ and Prxl genes was monitored on day 0, 3, 7 and 14 of ex vitro growth, by real time RT-PCR (Fig. 6) with primer design based on sugarcane sequences available on NCBI (http://www.ncbi.nlm.nih.gov/sites/entrez). On day 0, all the studied genes were up-regulated in GM as compared to TIB and most of them maintained higher levels of expression for the entire period of acclimatization. On day 0 Prx 1 expression in GM was only 10 fold higher than in TIB, increasing sharply to circa 80 fold on day 7. $A P X$, $C A T, C u Z n S O D$ and $G R$ transcripts were expressed more than 50 fold higher in GM on day 0 , and further increased their expression during acclimatization. Extreme responses were measured in $M n S O D$ and $C A T$, the first with an increase in expression levels reaching 1200 fold in GM and the second with the lowest levels of up-regulation in GM, between 7 and 20 fold and accounting for the only upregulation in TIB, on day 7 . 
Table 3 RuBisCO, PEPC and GR enzyme activity in bundle sheath and mesophyll tissues from sugarcane leaves. Relative values of fold variation between the two tissue types

\begin{tabular}{lccc}
\hline & RuBisCO & PEPC & GR \\
\hline Bundle sheath / Mesophyll & 3,5 & 0,44 & 1,5 \\
\hline
\end{tabular}

\section{Discussion}

The behaviour of sugarcane plantlets propagated in vitro using two distinct methods, GM and TIB, was compared during acclimatization to ascertain the efficiency of both micropropagation methods. Symptoms of photo-oxidative stress and the resulting response of the anti-oxidative system were monitored by ROS imaging, enzyme activities and gene expression of pathways affected by photooxidative stress and associated with recovery mechanisms.

In GM and TIB propagated plantlets, stomatal structures evidenced functional behaviour shown by the similar patterns of coloration with ROS staining dyes (Fig. 1) emerging in the cells surrounding the stomata. The major differences between the two treatments were observed in the stomatal and trichome indexes on day 0 of acclimatization, which corresponds to the last day in each of the propagation systems (Fig. 2). Leaves formed in GM showed significantly higher stomatal index corresponding

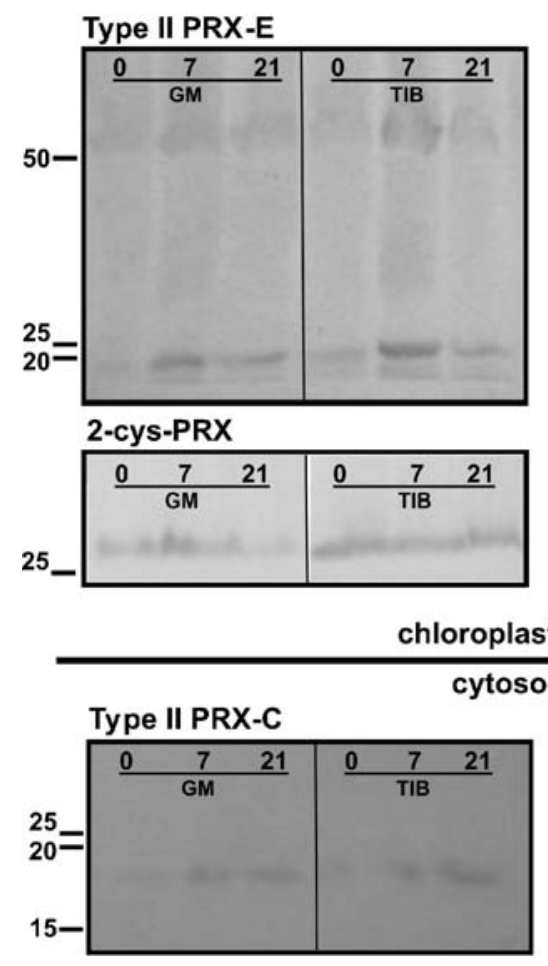

Fig. 5 Western blots of five different peroxiredoxins localized in three cellular compartments: chloroplast (2-cys Prx A; type II Prx E; Prx Q), cytosol (type II Prx C) and mitochondria (type II Prx F). Protein samples were subjected to SDS-page, transferred to a nitrocellulose membrane and probed with the specific antibodies. to a lower number of mesophyll cells and to larger intercellular spaces, as a direct consequence of lack of headspace ventilation [32], differing from those produced in TIB, whose indexes result from the presence of smaller cells and an anatomy similar to autotrophic leaves, observed on day 14 of ex vitro growth. Also, the much lower percentage of coloured stomata in TIB propagated plantlets on day 0 is probably related to a more advanced stomatal regulation provided by this propagation method. In GM propagated plantlets, almost $100 \%$ of the stomatal cells were stained on day 0 . The gain of function of functional stomata is recognizable by DAB staining since it has been shown that $\mathrm{H}_{2} \mathrm{O}_{2}$ triggers the activation of a signalling pathway over functional stomatal cells [49]. Later on, normal regulation of stomatal differentiation and functioning can proceed following the development of roots, new buds and the increase in ABA content [49], and DAB staining decreases, as was the case in GM propagated sugarcane.

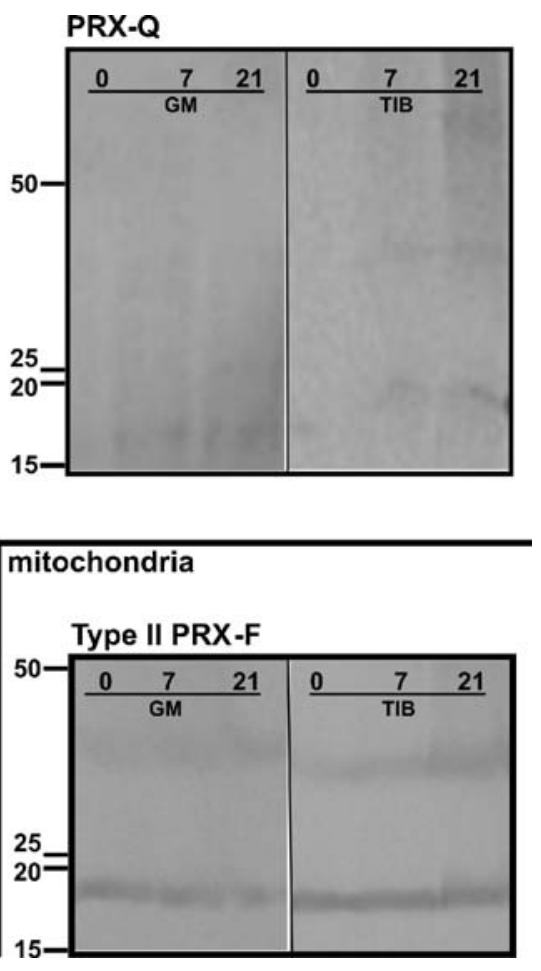

Western blots were performed in leaves of sugarcane plantlets propagated under both systems (GM and TIB) on day 0 of transfer to acclimatization and after 7 and 21 days of ex vitro growth. The numbers on the left side of each blot correspond to molecular weight $(\mathrm{kDa})$ 
Fig. 6 Changes in the expression levels of genes of the antioxidative system. Quantification of mRNA levels of those sugarcane genes was performed on day 0 of ex vitro growth after each propagation method (GM and TIB) and after 3, 7 and 14 days. mRNA was isolated from leaves, converted to cDNA, and subjected to realtime PCR. Relative amounts were calculated and normalized with respect to sugarcane Act2 mRNA. Each time point in each propagation method (GM and TIB) is compared to day 0 leaves propagated in GM (control, day $0=$ zero fold change). For clarity purposes, different scales were used. Values indicated by different letters are significantly different at $5 \%$ by C-Dunnett Multiple Range Test
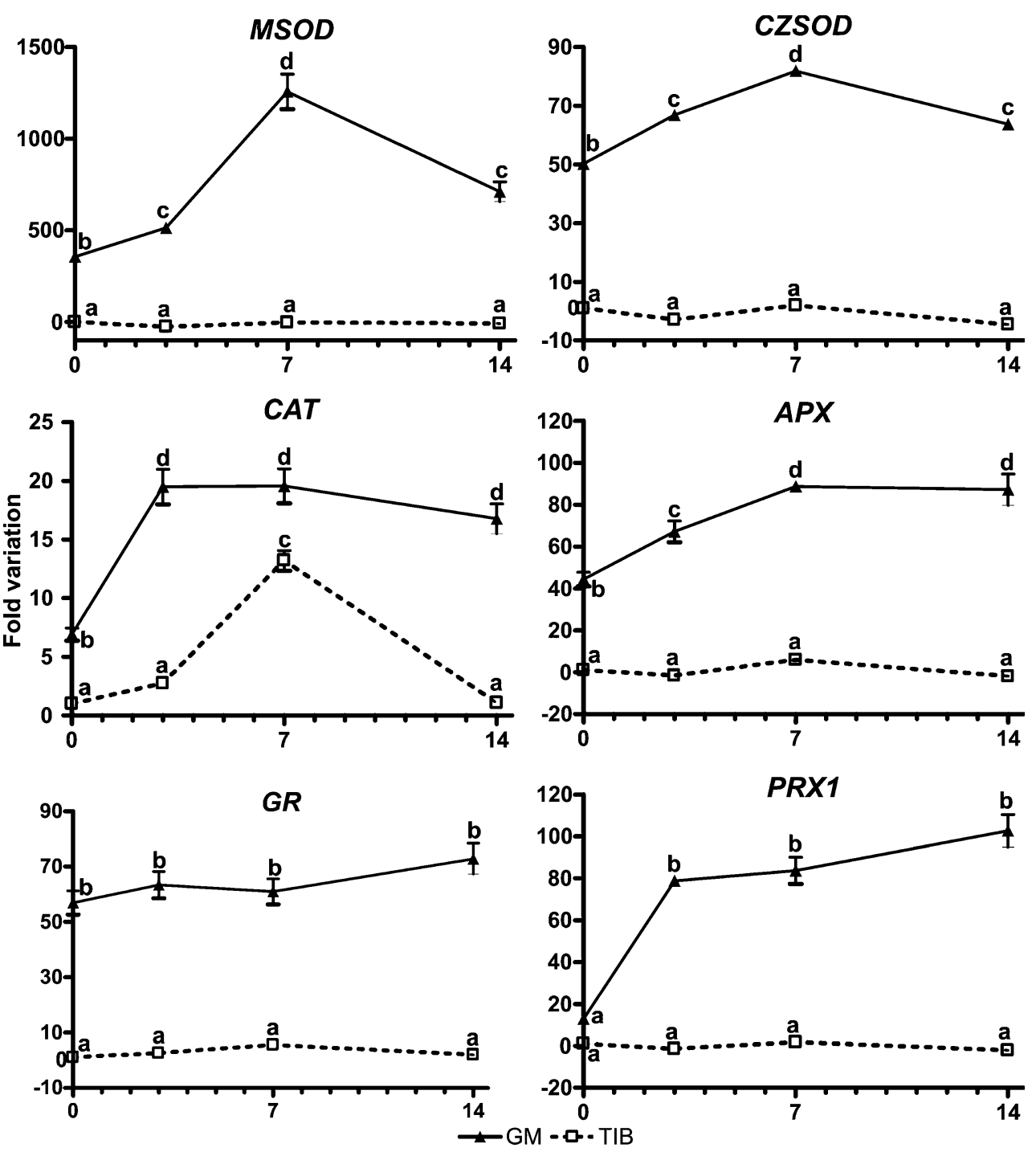

Time (days of acclimatization)

The glandular capacity of trichome structures was apparent in the second cell of the bicellular structure. This can be related with the maturation of trichomes as a response to light stress. Trichomes have the capacity to refract light and reduce the damage brought upon by leaf surface exposure to high light [50]. Glandular trichomes are modified epidermal cells that can also confer resistance to biotic stress [33], e.g. by entrapping insects in the polymerized trichome exudates [27]. Trichome index showed a pattern similar to the stomata one, with an additional factor: the death of trichomes during ex vitro growth of GM plantlets. Overall, the low stomatal and trichome numerical and staining indexes displayed by the leaves of plantlets under TIB on day 0, places them closer to authotrophic behaviour.

In vitro propagated plants can attain measurable photosynthetic rates, TIB giving rise to higher rates than GM (Aragón et al., unpublished data). However, at least in GM propagated plants, the $\mathrm{CO}_{2}$ fixation capacity does not curtail the symptoms of photoinhibition and oxidative stress that appear upon the higher light intensities applied at transfer [5, 7]. The anti-oxidative enzyme response triggered in the cells is a powerful tool to avoid the negative collateral effects of photo-oxidative stress. At the end of the in vitro phase (day 0) GM plants evidenced an activation of the $\mathrm{H}_{2} \mathrm{O}_{2}$ processing branch of the ascorbateglutathione cycle (higher APX and MDHAR activity), while TIB plants induced not only the DHAR/GR branch but also the activities of other response systems that contribute to curtail oxidative stress damage (CAT and GT, Fig. 3). This may explain why TIB plants transferred to ex vitro, evidencing high SOD activity, a scavenging strategy that seems to confer a more efficient response to the imposed photooxidative stress, still presented the expected sensitivity of APX to $\mathrm{H}_{2} \mathrm{O}_{2}$ [8]. Two of the $\mathrm{Cu}$ $\mathrm{Zn}$ SOD isoforms identified did not change their levels of 
activity while the inducible isoform responded to the acclimatization conditions. However, while in GM the variation in SOD activity matched the pattern of MnSOD, in TIB the increase in SOD activity was much higher than the isoform variation. Sugarcane leaves exposed to paraquat-induced oxidative stress also showed differences between the intensity of activity bands and total SOD activity, which can be explained by the lower sensitivity of the former method and/or the lack of detection of further isoforms [8]. In fact, seven $\mathrm{Cu}-\mathrm{Zn}$ isoforms were found in sugarcane seedlings under the effect of cadmium, although SOD activity remained constant [18]. In GM, particularly $M S O D$ but also $C Z S O D$, were significantly up-regulated in vitro, with the transcript of MnSOD still increasing significantly thereafter (Fig. 6). Apparently, TIB plantlets were able to keep high levels of SOD activity without the need to synthesize new enzyme molecules, since the levels of CZSOD and MSOD did not vary during the whole period. The level of expression and activity of MnSOD in GM plantlets reflects a sound development of the mitochondria, the cellular location of this isoenzyme [43]. However, heterotrophic behavior of GM plantlets, in favor of the anti-oxidative response at the mitochondrial level [37], is in addition an intrinsic characteristic of $\mathrm{C}_{4}$ metabolism, where mitochondria play an important role in the $\mathrm{CO}_{2}$ concentration cycle [30].

In gel GR activity revealed four isoforms, two located in the bundle sheath, and two from the mesophyll, all showing activity, $50 \%$ higher in bundle sheath cells. GR activity was not detected in the bundle sheath in a study designed to localize antioxidants in maize leaves [13], suggesting that the lack of NADPH in these tissues could explain the absence of GR activity. Also in maize, GR transcripts were present in the bundle sheath but no enzyme activity could be measured, probably due to postranscriptional regulation [38]. One difference between these studies and ours, where the co-existence of activity in the four isoenzymes of GR was found, is that they were performed in adult plants. The specialization of bundle sheath cells is achieved as a result of a combination of the procambial lineage with vein cells in adjacent position $[25,45]$. It is, therefore, expected to find differences between an adult plant and an in vitro propagated one, where specialized tissues are not yet fully developed. It is, in fact, interesting to notice that the bands for GR bundle sheath isoforms were fainter in TIB plants, probably due to a more advanced specialization than in GM.

Peroxiredoxins (Prxs) decompose ROS and lipid peroxides and tune them in signalling events. Their total activity decreased throughout acclimatization in both treatments (Fig. 3). All higher plant Prxs are nuclear-encoded proteins [11] and to distinguish the presence of Prxs targeted to different cellular compartments, we used specific antibodies for five Prxs. Chloroplast located 2-cys Prx A showed a defined pattern with significantly higher quantities in TIB propagated plantlets. Also, chloroplast type II Prx E and Prx Q were almost absent in GM and showed polymerization in TIB propagated plantlets. This shows that TIB not only induced a pronounced antioxidative response at the level of the chloroplast, but also induced the polymerization of enzymes that in GM plantlets were poorly represented. Mitochondria revealed a pattern similar to the one observed in chloroplasts, with clear polymerization of type II Prx F, and a stronger signal in TIB propagated plantlets. This Prx, the only one targeted to the mitochondria in Arabidopsis, is an important component of the mitochondrial defense system against peroxide stress [17]. As a whole, GM propagated plantlets evidenced low Prx activity, consistent with the low quantities of the enzymes, which did not show polymerization, although higher levels of the correspondent transcripts were measured, while TIB propagated plantlets also showed low enzyme activity, together with basal expression levels and higher quantity of protein, which displayed polymerization. Prx polymerization is a consequence of an oxidative environment in the chloroplast and mitochondria, and can be used as a marker for oxidative stress [21]. These results, once more, point to the conclusion that the anti-oxidative response of GM plantlets was strongly up-regulated at the transcription level without the corresponding activity of translated proteins, due to post-transcriptional or posttranslation regulation. The hypothesis that $\mathrm{H}_{2} \mathrm{O}_{2}$ can behave as a signal for triggering the transcription of anti-oxidant genes [35] seems to be confirmed in GM plants.

The overall upregulation of transcripts in GM plantlets (Fig. 6) must indicate a much higher induction of the antioxidative genes than in TIB propagated plantlets. The lack of upregulation reported in TIB can be explained by the previous acclimation to patterns of gas exchange much closer to ex vitro environment [26].

Until the present work, no studies had been performed to unravel the pattern of oxidative stress response and recovery responsible for the consensual empirical opinion that TIB techniques prove to be better propagation systems than GM. Previous studies supporting that opinion studied the morphology [31, 41] and the photosynthetic capacity [2]. With the present work we showed evidence that TIB propagated sugarcane plants present, at the moment of transfer to ex vitro conditions, functional stomata and trichome structures with characteristics similar to ex vitro plants, helping them cope with the stress imposed upon by acclimatization. Contrary to what happened in GM, TIB plantlets maintained the anti-oxidative system activated from the in vitro phase, and the major ROS scavenger, SOD, was present at high levels of activity until the end of acclimatization. In the mesophyll and bundle sheath, and 
within the different cell compartments, $\mathrm{H}_{2} \mathrm{O}_{2}$ produced by high SOD activity can be processed by the GR branch of the ascorbate-glutathione cycle and/or by CAT and Prx. The polymerization of Prx is, apparently, a transient solution for the oxidative environment in chloroplast and mitochondria. All these data put in evidence the better preparation of TIB plantlets to cope with the stress of acclimatization and the adjustment of their autotrophic behaviour to the antioxidative response to ex vitro environment.

Acknowledgments To the Program Alban, the European Union Program of High Level Scholarships for Latin American, scholarship number E06D100217CU to C.A; "Fundação para a Ciência e Tecnologia", for the post-doc grant SFRH/BPD/5707/2001 to L.C. and Plurianual funds to CBAA.

\section{References}

1. Anderson M, Prasad T, Stewart C (1995) Changes in isozyme profiles of catalase, peroxidase and glutathione reductase during acclimation to chilling in mesocotyls of maize seedlings. Plant Physiol 109:1247-1257

2. Aragón C, Escalona M, Capote I, Pina P, Cejas I, Rodríguez R, Cañal M, Sandoval J, Roels S, Debergh P, González-Olmedo J (2005) Photosynthesis and carbon metabolism in Plantain (Musa $\mathrm{AAB}$ ) growing in Temporary Immersion Bioreactor (TIB) and $e x$ vitro acclimatization. In Vitro Cell Dev Biol Plant 41:550-554 doi:10.1079/IVP2005640

3. Bioethanol productions (2007) http://www.bioethanol.com.ph

4. Bradford MM (1976) A rapid and sensitive method for the quantification of microgram quantities of protein utilizing the principle of protein dye binding. -. Anal Biochem 72:248-254 doi:10.1016/0003-2697(76)90527-3

5. Carvalho L, Santos P, Amâncio S (2002) Effects of light intensity and $\mathrm{CO}_{2}$ concentration on growth and the acquisition of in vivo characteristics during acclimatization of grapevine regenerated in vitro. Vitis $41: 1-6$

6. Carvalho L, Esquível MG, Amâncio S (2005) Stability and activity of Rubisco in chestnut plantlets transferred to ex vitro under elevated $\mathrm{CO}_{2}$. In Vitro - . Plant 41:523-531

7. Carvalho L, Vilela J, Vidigal P, Mullineaux P, Amâncio S (2006) Activation of the ascorbate-glutathione cycles is an early response of micropropagated Vitis vinifera $\mathrm{L}$. explantlets transferred to ex vitro. Int J Plant Sci 167:759-770 doi:10.1086/503919

8. Chagas R, Silveira J, Ribeiro R, Vitorello V, Carrer H (2008) Photochemical damage and comparative performance of superoxide dismutase and ascorbate peroxidase in sugarcane leaves exposed to paraquat-induced oxidative stress. Pestic Biochem Physiol 90:181-188 doi:10.1016/j.pestbp.2007.11.006

9. Chang S, Puryear J, Cairney J (1993) A simple and efficient method for isolating RNA from pine trees. Plant Mol Biol Rep 11:113-116 doi:10.1007/BF02670468

10. Dalton D, Baird L, Langeberg L, Taughet C, Anyan W, Vance C, Sarath G (1993) Subcellular localization of oxygen defence 21 enzymes in soybean (Glycine max L. Merr.) root nodules. Plant Physiol 102:481-489

11. Dietz K-J (2003) Plant peroxiredoxins. Annu Rev Plant Biol 54:93-107 doi:10.1146/annurev.arplant.54.031902.134934

12. Donahue J, Okpodu C, Cramer C, Grabau E, Alscher R (1997) Responses of antioxidants to paraquat in pea leaves: relationships to resistance. Plant Physiol 113:249-257
13. Doulis A, Debian N, Kingston-Smith A, Foyer CH (1997) Differential localization of antioxidants in maize leaves. Plant Physiol 114:1031-1037

14. Drotar A, Phelbs P, Fall R (1985) Evidence for glutathione peroxidase activities in culture plant cells. Plant Sci 42:35-40 doi:10.1016/0168-9452(85)90025-1

15. Escalona M, Samson G, Borroto C, Desjardins Y (2003) Physiology of the effects of Temporary Immersion Bioreactors on micropropagated pineapple plantlets. In Vitro Cell Dev Biol Plant 39:651-656 doi:10.1079/IVP2003473

16. Ferreira R, Franco E, Teixeira A (1996) Covalent dimerization of ribulose bisfosphate carboxylase subunits by UV radiation. Biochem J 318:227-234

17. Finkemeier I, Goodman M, Lamkemeyer P, Kandlbinder A, Sweetlove LJ, Dietz KJ (2005) The mitochondrial type II peroxiredoxin $\mathrm{F}$ is essential for redox homeostasis and root growth of Arabidopsis thaliana under stress. J Biol Chem 280:12168-12180 doi:10.1074/jbc.M413189200

18. Fornazier RF, Ferreira RR, Vitória AP, Molina SMG, Lea PJ, Azevedo RA (2002) Effects of cadmium on antioxidant enzyme activities in sugar cane. Biol Plant 45:91-97 doi:10.1023/ A:1015100624229

19. Fryer M, Oxborough K, Mullineaux P, Baker N (2002) Imaging of photoxidative stress responses in leaves. J Exp Bot 53:1249-1254 doi:10.1093/jexbot/53.372.1249

20. Gratao P, Polle A, Lee P, Azevedo R (2005) Making the life of heavy-metal stressed plants a little easier. Funct Plant Biol 32:481-494 doi:10.1071/FP05016

21. Heiber I, Ströher E, Raatz B, Busse I, Kahmann U, Bevan M, Dietz KJ, Baier M (2007) The redox imbalanced Mutants of Arabidopsis Differentiate Signaling Pathways for Redox Regulation of chloroplast antioxidant enzymes. Plant Physiol 143:17741788 doi:10.1104/pp.106.093328

22. Horling F, Lamkemeyer P, Konig J, Finkemeier I, Kandlbinder A, Baier M, Dietz KJ (2003) Divergent Light-, Ascorbate-, and Oxidative Stress-Dependent Regulation of expression of the Peroxiredoxin Gene Family in Arabidopsis. Plant Physiol 131:317-325 doi:10.1104/pp.010017

23. Hossain M, Asada A (1984) Inactivation of ascorbate peroxidase in spinach chloroplasts on dark addition of hydrogen peroxide: its protection by ascorbate. Plant Cell Physiol $25: 1285-1295$

24. Jackson M, Abbott A, Belcher A, Hall K, Butler R, Cameron J (1991) Ventilation in plant tissue cultures and effects of poor aeration on ethylene and carbon dioxide accumulation, oxygen depletion and explant development. Annal Bot 67:229-237

25. Jankovsky JP, Smith LG, Nelson T (2001) Specification of bundle sheath cell fates during maize leaf development: Roles of lineage and positional information evaluated through analysis of the tangled mutant. Develop 128:2747-2753

26. Kozai T, Zobayed S (2000) Acclimatization. In: Spier RE (ed) Encyclopedia of Cell Technology, John Wiley \& Sons, Inc, pp1-12

27. Kowalski S, Eannetta N, Hirzel A, Steffens J (1992) Purification and Characterization of Polyphenol Oxidase from Glandular Trichomes of Solanum berthaultii. Plant Physiol 100:677-684

28. Laemmli UK (1970) Cleavage of structural proteins during the heat of bacteriophage T4. Nature 227:680-685 doi:10.1038/ $227680 \mathrm{a} 0$

29. Leegood R (1985) The intercellular compartmentation of metabolites in leaves of Zea mays L. Planta 164:163-171 doi:10.1007/ BF00396078

30. Leegood RC (2002) $\mathrm{C}_{4}$ photosynthesis: principles of $\mathrm{CO}_{2}$ concentration and prospects for its introduction into $\mathrm{C}_{3}$ plants. $\mathrm{J}$ Exp Bot 53:581-590 doi:10.1093/jexbot/53.369.581

31. Lorenzo J, Blanco M, Peláez O, González A, Cid M, Iglesias A, González B, Escalona M, Espinosa P, Borroto C (2001) Sugarcane 
micropropagation and phenolic excretion. Plant Cell Tissue Organ Cult 65:1-8 doi:10.1023/A:1010666115337

32. Majada JP, Tadeo F, Fal MA, Sánchez-Tamés R (2000) Impact of culture vessel ventilation on the anatomy and morphology of micropropagated carnation. Plant Cell Tiss Org Cult 63:207-214

33. Martin C, Glover BJ (2007) Functional aspects of cell patterning in aerial epidermis. Curr Opin Plant Biol 10:70-82 doi:10.1016/j. pbi.2006.11.004

34. McCord J, Fridovich I (1969) Superoxide dismutase: an enzymic function for erythrocuprein. J Inorg Biochem 244:6049-6055

35. Mullineaux PM, Karpinski S, Baker N (2006) Spatial dependence for hydrogen peroxide-directed signalling in light stressed plants. . Plant Physiol 141:346-350 doi:10.1104/pp.106.078162

36. Murashige T, Skoog F (1962) A revised medium for rapid growth and bio assays with tobacco tissue cultures. Physiol Plant 15:473497 doi:10.1111/j.1399-3054.1962.tb08052.x

37. Noctor G, Paepe R, Foyer CH (2007) Mitochondrial redox biology and homeostasis in plants. Trends Plant Sci 12:125-134 doi:10.1016/j.tplants.2007.01.005

38. Pastori G, Mullineaux P, Foyer CH (2000) Post-Transcriptional Regulation Prevents Accumulation of Glutathione Reductase Protein and Activity in the Bundle Sheath Cells of Maize. Plant Physiol 122:667-675 doi:10.1104/pp.122.3.667

39. Pérez C (2005) Técnicas estadísticas con SPSS 12. Aplicaciones al análisis de datos. ISBN 84-205-4410-8. Pearson Educación SA (ed), Spain

40. Rao M, Paliyath G, Ormrod D (1996) Ultraviolet-B- and ozoneinduced biochemical changes in antioxidant enzymes of Arabidopsis thaliana. Plant Physiol 110:125-136 doi:10.1104/ pp.110.1.125

41. Rodriguez R, Cid M, Pina D, Gonzalez-Olmedo J, Desjardins Y (2003) Growth and photosynthetic activity during acclimatization of sugarcane plantlets cultivated in Temporary Immersion bioreactors. In Vitro Cell Dev Biol Plant 39:657-662 doi:10.1079/IVP2003472
42. Roels S, Noceda C, Escalona M, Sandoval J, Canal MJ, Rodriguez R, Debergh PC (2006) The effect of headspace renewal in a temporary immersion bioreactor on plantain (Musa AAB) shoot proliferation and quality. Plant Cell Tissue Organ Cult 84:155-163 doi:10.1007/s11240-005-9013-y

43. Ruth A, Neval E, Lendwood H (2002) Role of superoxide dismutase (SODs) in controlling oxidative stress in plants. J Exp Bot 53:1331-1341 doi:10.1093/jexbot/53.372.1331

44. Schaedle M, Bassham J (1977) Chloroplast glutathione reductase. Plant Physiol 59:1011-1012

45. Smith LG, Hake S, Sylvester AW (1996) The tangled-1 mutation alters cell division orientations throughout maize leaf development without altering leaf shape. Develop 122:481489

46. Tanaka Y, Sano T, Tamaoki M, Nakajima N, Kondo N, Hasezawa S (2005) Ethylene Inhibits Abscisic Acid-Induced Stomatal Closure in Arabidopsis. Plant Physiol 138:2337-2343 doi:10.1104/pp.105.063503

47. van Huylenbroeck JM, Piqueras A, Deberg PC (2000) The evolution of photosynthetic capacity and the antioxidant enzymatic system during acclimatization of micropropagated Calathea plants. Plant Sci 135:59-66 doi:10.1016/S0168-9452 (00)00201-6

48. Van Quy L, Lamaze T, Champigny ML (1991) Effect of light and $\mathrm{NO}_{3}{ }^{-}$on wheat leaf phosphoenolpyruvate carboxylase activity. Evidence for covalent modulation of the $\mathrm{C}_{3}$ enzyme. Physiol Plant 97:1476-1482

49. Vilela J, Carvalho L, Ferreira J, Amâncio S (2007) Gain of function of stomatal movements in rooting Vitis vinifera $\mathrm{L}$ plantlets: regulation by $\mathrm{H}_{2} \mathrm{O}_{2}$ is independent of $\mathrm{ABA}$ before the protruding of roots. Plant Cell Rep 26:2149-2157 doi:10.1007/ s00299-007-0427-3

50. Wagner G (1991) Secreting Glandular Trichomes: More than Just Hairs. Plant Physiol 96:675-679 